\title{
Unusual Bones Articulating With the Pelvic Girdle
}

Authors: Otsyeno FMT' ${ }^{1}$, MBChB, MMed (Surg), FCS (ECSA), SICOT(Dip) Atinga JE0 ${ }^{\mathbf{1}, \mathbf{2}}$, MBChB, MMed (Surg), Mch(Ortho)

Affiliations 1- Kenyatta National Hospital 2- Department of Orthopaedics, College of Health Sciences University of Nairobi Correspondence: Otsyeno FMT, P.0 BOX 29803 -00202 (Kenyatta National Hospital),Nairobi, E-mail Otsyeno@hotmail.com

\section{Summary}

We report a case of a 44 year old man who presented with right gluteal pain following trivial trauma, associated with unusual bones, with all the characteristics of clavicles articulating with the pelvic girdle. The pain on that side was completely relieved by excision of the bone.

\section{Introduction}

Buttock pain is commonly traced to low back conditions $(1,2)$. Few local conditions offer differential diagnosis in an otherwise healthy individual. These include gluteal abscess and sciatic entrapment neuropathy $(1,2)$. Symptomatic accessory girdle bones have been described for the pectoral girdle but none for the pelvis $(3,4)$. Accessory pelvic bones may offer further differentials in the evaluation of buttock pain in healthy individuals.

\section{Case Report}

Mr. X was a 44 year old male who presented with right buttock pain for three weeks after he fell from a chair and landed on his right buttock. The pain was dull and non- radiating. He reported discomfort whenever he sat on a firm surface for periods lasting more than $30 \mathrm{~min}$ utes. There was no significant past medical or surgical history.

\begin{tabular}{lll} 
Test & Results & Normal range \\
\hline Haemoglobin level & $14.2 \mathrm{~g} / \mathrm{dl}$, & $12-16 \mathrm{~g} / \mathrm{dl}$ \\
\hline White cell count & 6.2 & $4.8-10.8$ \\
\hline ESR & $16 \mathrm{~mm} / \mathrm{hr}$, & less than 20 \\
\hline Albumen & $45 \mathrm{~g} / \mathrm{l}$, & $34-52 \mathrm{~g} / \mathrm{l}$ \\
\hline Total Protein & $73 \mathrm{~g} / \mathrm{l}$ & $60-87 \mathrm{~g} / \mathrm{l}$ \\
\hline Calcium & $2.02 \mathrm{mmo} / \mathrm{l}$, & $2.02-2.65 \mathrm{mmol} / \mathrm{L}$ \\
\hline Phosphate & $1.09 \mathrm{mmol} / \mathrm{l}$ & $0.81-1.62 \mathrm{mmol} / \mathrm{l}$ \\
\hline Alkaline phosphates & $178 \mathrm{u}$ & $80-306 \mathrm{u}$ \\
\hline
\end{tabular}

Table I: Haematological and Biochemical findings
On physical examination, he was a middle aged man in good general condition, good nutrition and no stigmata of chronic disease. He weighed $98 \mathrm{Kg}$ and was $1.72 \mathrm{M}$ tall [body mass index of 33.12]. He had no lymphadenopathy, finger clubbing or jaundice. His vital signs were within normal range.

Local examination was significant for disproportionate gluteal folds. Superficial and deep palpation did not reveal the presence of masses. There was no tenderness. His haematological and biochemical investigations were all normal (Table 1). The urine analysis was normal.

Pelvic radiographs demonstrated accessory pelvic bones, with all the appearances of clavicles, articulating with the pelvic girdle. Unlike in the normal clavicle, these bones were on the posterior aspects of the innonimate bones, one articulated with the sacrum and the other with the ilium rather than the pubic symphysis (Fig. 1)

The patient was appraised of the clinical and radiological findings and counselled for surgery. He consented to surgery on the symptomatic right. Total excision of the bone, morphologically akin to the clavicle with no muscles attached to it, was performed (Fig. 2). The patient made an event free recovery. He has no pain on follow up. Histology confirmed normal bone tissue.

\section{Discussion}

The clavicle or collar bone is classified as a long bone that makes up part of the shoulder girdle (pectoral girdle) (5) It receives its name from the Latin clavicula (5, 6) ("little key") because the bone rotates along its axis like a key when the shoulder is abducted. Duplication of the clavicle has been described in only six reports based 


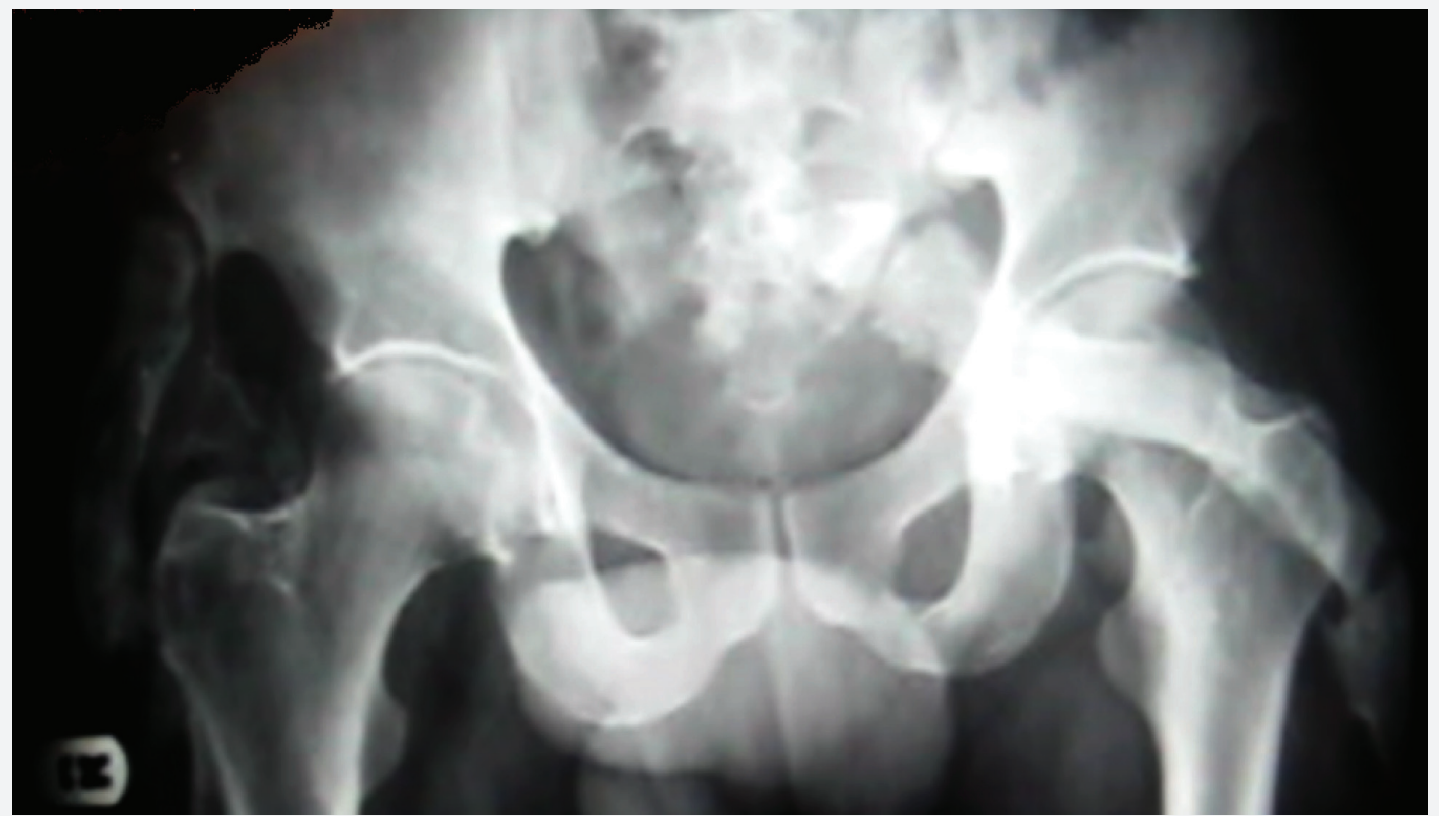

Fig. 1 Pelvic radiograph demonstrating accessory clavicle-like bones

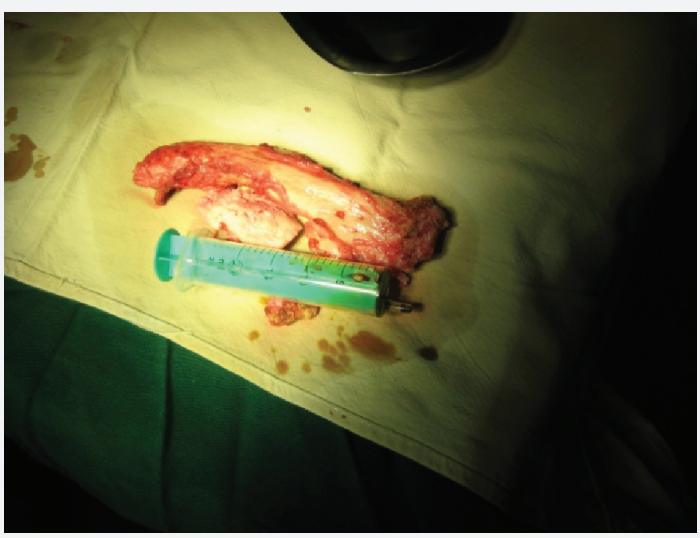

Fig. 2 Bone with all the appearance of the clavicle excised from the right gluteal region of $\mathrm{Mr} \mathrm{X}$

on a search of the world literature (3). In children with outer third clavicular injuries, duplication or neoclavicle formation has been documented to rarely complicate the clavicular fracture (4). These accessory clavicles have only been described in the region of the pectoral girdle $(3,4)$. We report a case of bilateral accessory bones, with all the appearances of clavicles, articulating with the pelvic girdle in a patient who was otherwise normal. A search in the literature indicates that this is the first report of such an appearance. The pain seems to have been caused by the trauma suffered on the accessory bone considering that it was not as heavily covered by the gluteal musculature as is the case of the other pelvic bones.

\section{References}

1. van den Hoogen HM, Koes BW, van Eijk JT et al. On the accuracy of history, physical examination, and erythro- cyte sedimentation rate in diagnosing low back pain in general practice. A criteria-based review of the literature. Spine. 1995; 20:318-27.

2. Vroomen PC, de Krom MC, Knottnerus JA. Diagnostic value of history and physical examination in patients suspected of sciatica due to disc herniation: a systematic review. J Neurol. 1999; 246:899-906.

3. Sharma BG Duplication of the clavicle with triplication of the coracoid process. Skeletal radiology 2003 32.661664

4. Joshy S., Iossifidis A. and Ebrahim S. Post-traumatic duplication of the clavicle. Injury, 2005; $2 .: 20$

5. Moore, Keith L. and Arthur F. Dalley. Clinically Oriented Anatomy, 4th edition.Lippincott Wilkins, 1999, 4th Ed.

6. Stedman's Medical Dictionary, 27th edition. Lippincott Wilkins, 2003 